\title{
Role of Adipokines in the Association between Thyroid Hormone and Components of the Metabolic Syndrome
}

\author{
Alessandro P. Delitala ${ }^{1,2, *}$, Angelo Scuteri ${ }^{3}$, Edoardo Fiorillo ${ }^{1}$, Edward G. Lakatta ${ }^{4}$, \\ David Schlessinger ${ }^{5}$ and Francesco Cucca ${ }^{1,6}$ \\ 1 Istituto di Ricerca Genetica e Biomedica (IRGB), Consiglio Nazionale delle Ricerche, \\ c/o Cittadella Universitaria di Monserrato, 09042 Cagliari, Italy; edoardofiorillo@gmail.com (E.F.); \\ fcucca@uniss.it (F.C.) \\ 2 Department of Medicine Azienda Ospedaliero-Universitaria di Sassari, 07100 Sassari, Italy \\ 3 Department of Clinical and Experimental Medicine, University of Sassari, 07100 Sassari, Italy; \\ d341elefante@virgilio.it \\ 4 Laboratory of Cardiovascular Science, National Institute on Aging, National Institute of Health, \\ Baltimore, MD 21224, USA; LakattaE@grc.nia.nih.gov \\ 5 Department of Health and Human Services, National Institute on Aging, NIH, Baltimore, MD 21224, USA; \\ SchlessingerD@grc.nia.nih.gov \\ 6 Department of Biomedical Sciences, University of Sassari, 07100 Sassari, Italy \\ * Correspondence: aledelitala@tiscali.it; Tel.: +39-079-228-184 or +39-079-228-207
}

Received: 21 April 2019; Accepted: 28 May 2019; Published: 30 May 2019

check for updates

\begin{abstract}
Metabolic syndrome (MS) increases cardiovascular risk. The role of thyroid hormone on components of MS is unclear. We analyzed a sample of 4733 euthyroid subjects from SardiNIA study. In female thyrotropin (TSH) was significantly and positively associated with triglycerides (Standardized regression coefficients $(\beta)=0.081, p<0.001)$. Free thyroxine (FT4) was positively associated with HDL $(\beta=0.056, p<0.01)$, systolic blood pressure (SBP) $(\beta=0.059, p<0.001)$, diastolic blood pressure (DBP) $(\beta=0.044, p<0.01)$, and fasting glucose $(\beta=0.046, p<0.01)$. Conversely, FT4 showed a negative association with waist circumference $(\beta=-0.052, p<0.001)$. In TSH was positively associated with triglycerides $(\beta=0.111, p<0.001)$ and FT4 showed a positive association with $\mathrm{DBP}(\beta=0.51, p<0.01)$. The addition of leptin and adiponectin to the regression models did not substantially change the impact of thyroid hormones on components of MS. Our data suggest that, even within the euthyroid range, excess of truncal adipose tissue is associated with variations in FT4. Leptin and adiponectin exert an additive effect rather than a causal effect. Additional studies should be performed to determine the clinical significance of this finding.
\end{abstract}

Keywords: free thyroxine; thyrotropin; metabolic syndrome; leptin; adiponectin

\section{Introduction}

Metabolic syndrome (MS) is characterized by a cluster of cardiovascular risk factors, which increases the risk of cardiovascular disease (CVD) [1-3]. A clinical definition of the MS has been developed in the last two decades with the purpose of identifying those individuals at increased risk of these diseases in order to put in place preventive measures that can reduce this risk [4]. These risk factors include impaired glycemia, raised blood pressure, elevated triglyceride levels, low high-density lipoprotein cholesterol levels (HDL) and abdominal obesity (which is highly correlated with insulin resistance). The National Cholesterol Education Program (NCEP) Adult Treatment Panel III (ATP III) guidelines define MS as having three of these 5 modifiable risk factors. 
Once CVD or diabetes develops, the MS is often present, and the number of components of the MS contributes to disease progression and risk [5].

Thyroid hormone is an important regulator of cardiac function and changes in its concentration are associated with several alterations in cardiovascular hemodynamic. Metabolic changes found in MS are similar to those seen in overt hypothyroidism [6], but it has been still a concern for subclinical disorders [7,8]. Evidences suggest that disorders of the thyroid gland are associated with alterations in lipid metabolism, blood pressure, and increased cardiovascular risk $[9,10]$. Recent studies have shown that thyroid dysfunction can induce insulin resistance, but the evidences are not univocal [11]. Thus, MS shared common features with thyroid disorders, both being a risk factor of cardiovascular disease. MS has been associated with subclinical thyroid disease in adults due to the effect of thyroid function on cardiovascular dysfunction, lipid and glucose metabolism, and blood pressure [12]. There are few studies addressing the relation between thyroid function and MS in euthyroid subjects. Some authors reported an association between thyrotropin (TSH) and MS [13,14], some reported an association with free thyroxine (FT4) $[15,16]$ and others did not find any $[17,18]$. The role of adipokines, leptin and adiponectin in particular, on metabolic syndrome is well acknowledged. Leptin has been found increased in subjects with hyperinsulinemia and type 2 diabetes, and showed a positive association with triglycerides, systolic and diastolic blood pressure [19]. On the other hand, adiponectin, whose levels are inversely related with visceral fat, has anti-atherogenic and anti-diabetic properties. Reduced levels are associated in some obesity-related disorders including hypertension [20] and type 2 diabetes mellitus [21]. Recently, leptin-adiponectin ratio (1/a) emerged as a good predictor of MS and type 2 diabetes, stronger than leptin and adiponectin alone [22].

In this study we aimed to clarify the relation between normal thyroid function, leptin and adiponectin with components of MS using a large cohort of euthyroid subjects from the general population.

\section{Experimental Section}

\subsection{Participants and Data Recorded}

The cohort is from the SardiNIA study, a population-based survey that investigates hundreds of genetic and phenotypic age-related traits [23]. Briefly, from 2001-2004, all residents in four towns of Lanusei valley (Lanusei, Arzana, Ilbono, and Elini) aged 14 years and older were invited to participate. In all, 6148 subjects were recruited, approximately $62 \%$ of the eligible population. For our analyses, subjects not being euthyroid and those using thyroid medications were excluded, as well as subjects taking glucose lowering medication, subjects taking lipid-lowering drugs and those who were on antihypertensive therapy, yielding a sample of 4733 subjects.

Each participant provided their informed consent. All study methods were conducted according to the principles expressed in the Declaration of Helsinki and were approved by the governing Ethics Committee, Azienda Sanitaria Locale (ASL 4).

\subsection{Laboratory Measurements}

Blood venous samples were drawn between 7 and 8 a.m. after an overnight fast. Serum samples were stored at $-80^{\circ} \mathrm{C}$ until use. TSH assessed with the Siemens TSH assay (Immulite 2000, Siemens, Healthcare Diagnostics Inc., Tarrytown, NY, USA) according to manufacturer's instructions. The method is a solid-phase, two-site chemiluminescent immunometric assay (normal range 0.4-4.0 $\mu \mathrm{IU} / \mathrm{mL}$ ). FT4 was measured with the Siemens FT4 assay (Immulite 2000, Siemens, Healthcare Diagnostics Inc., Tarrytown, NY, USA). The method is a solid-phase, enzyme labelled chemiluminescent competitive immunoassay (normal range $0.89-1.76 \mathrm{ng} / \mathrm{dL}$ ).

Plasma triglycerides and total cholesterol were determined by an enzymatic method (Abbott Laboratories ABA-200 ATC Biochromatic Analyzer, Irving, TX, USA). High-density lipoprotein (HDL) cholesterol was determined by dextran sulphate-magnesium precipitation [24]. Low-density 
lipoprotein (LDL) cholesterol was estimated by the Friedewald formula [25], calculated as follows: LDL cholesterol $=$ total cholesterol $-($ HDL cholesterol $+($ triglycerides/5) $)$. Fasting plasma glucose concentration was measured by the glucose oxidase method (Beckman Instruments Inc., Fullerton, CA, USA). Leptin and adiponectin (human serum adipokine-panel B; Lincoplex kit-Linco Research, Inc., 14 Research Park Dr., St. Charles, MO 63304, USA: Cat. \# HADK2-61K-B) were measured with a multiplex testing Luminex Model no. Luminex 200 IS Serial No. LX10006265401 (Luminex Corporation, Austin, TX, USA).

\subsection{Definitions}

Euthyroidism was diagnosed in subjects with TSH within the reference range $(0.4-4.0 \mu \mathrm{IU} / \mathrm{mL})$, while not taking any thyroid therapy. Waist circumference $(\mathrm{cm})$ was measured on bare skin between the $10^{\text {th }}$ rib and the iliac crest at the end of normal expiration. The homeostasis model assessment (HOMA) index was calculated as fasting glucose $(\mathrm{mg} / \mathrm{dL})$ times fasting insulin $(\mathrm{mU} /$ liter) divided by 405 [26].

The MS criteria was considered according to ATP III [27] and defined as the presence of at least three of the following five items: (1) abdominal obesity, defined as waist circumference in men greater than $102 \mathrm{~cm}$ and in women greater than $88 \mathrm{~cm}$; (2) serum triglycerides $\geq 150 \mathrm{mg} / \mathrm{dL}$; (3) serum HDL less than $40 \mathrm{mg} / \mathrm{dL}$ in men and less than $50 \mathrm{mg} / \mathrm{dL}$ in women; (4) systolic blood pressure (SBP) $\geq 130 \mathrm{mmHg}$ or diastolic blood pressure (DBP) $\geq 85 \mathrm{mmHg}$; (5) fasting glucose $\geq 110 \mathrm{mg} / \mathrm{dL}$.

Overweight was defined by the presence of $\mathrm{BMI} \geq 25 \mathrm{Kg} / \mathrm{m}^{2}$.

\subsection{Statistical Analysis}

Normality was tested by the Shapiro-Wilk test for all the continuous variables under study. Because all of them had non-normal distribution nonparametric tests were used. Accordingly, median and interquartile range (IQR) were utilized as summary measures. Differences among male and female in continuous variable were tested using Kruskal-Wallis test. Fisher's exact test was used to test differences in frequency. Linear regression models were performed to assess the association between components of metabolic syndrome (dependent variable) and thyroid hormone. Analyses were conducted for male and female, testing separately TSH and FT4. We created three different models: model 1, was adjusted for age, overweight, and HOMA-index; model 2 adjusted for age, overweight, HOMA index, leptin and adiponectin; model 3 adjusted for age, overweight, HOMA, leptin-adiponectin ratio. We also tested the interactive effect of thyroid hormone and cytokines on the components of metabolic syndrome entering appropriate interaction terms in all the analysis (TSH-by-leptin, TSH-by-adiponectin, TSH-by-1/a, FT4-by-leptin, FT4-by-adiponectin, FT4-by-1/a).

Results of regression models in the text were reported as standardized regression coefficients $(\beta)$ and $p$ value, which was set at $<0.05$ in Stata 12.0 (StataCorp LLC, College Station, TX, USA).

\section{Results}

Descriptive statistics, stratified by gender, are provided in Table 1 and Figure 1 . The overall prevalence of metabolic syndrome in the sample was $4.3 \%$. Both male and female participants had comparable age, total cholesterol, and fasting insulin levels. Females had lower BMI and waist circumference and had lower blood pressure values $(p<0.001$ for all). On the contrary males had a worst lipid status: higher LDL, triglycerides, and lower HDL ( $p<0.001$ for all). Females had higher TSH values, showed lower fasting glucose concentration $(p<0.001$ for all) and a lower HOMA index $(p<0.01)$. Finally, Female had higher leptin and adiponectin levels as compared to male $(p<0.001$ for both). 
Table 1. Descriptive characteristics of cardiovascular risk factors of the sample.

\begin{tabular}{|c|c|c|c|}
\hline & Female & Male & Total \\
\hline$n$ & 2628 & 2105 & 4733 \\
\hline Age (yrs.) & $37.6(27.2-50.4)$ & $39.1(27.6-52.2)$ & $38.3(27.4-51.3)$ \\
\hline $\operatorname{BMI}\left(\mathrm{Kg} / \mathrm{m}^{2}\right)$ & $23.1(20.6-26.2)$ & $25.5(22.9-28.1)$ & $24.2(21.5-27.4)^{\mathbb{I}}$ \\
\hline Waist (cm) & $76.0(70.0-85.0)$ & $89.0(81.0-96.0)$ & $82.0(73.0-92.0)^{\text {II }}$ \\
\hline $\mathrm{SBP}(\mathrm{mmHg})$ & $117(108-127)$ & $127(118-137)$ & $120(111-132)^{\mathbb{I I}}$ \\
\hline $\mathrm{DBP}(\mathrm{mmHg})$ & $72(69-80)$ & $79(70-86)$ & $75(70-82) \mathbb{I}$ \\
\hline Total cholesterol (mg/dL) & $204(177-231)$ & $206(174-238)$ & $205(176-234)$ \\
\hline $\mathrm{LDL}(\mathrm{mg} / \mathrm{dL})$ & $120(99-144)$ & 127 (102-153) & $123(100-148)$ II \\
\hline HDL (mg/dL) & $67(58-77)$ & $57(49-66)$ & $63(53-73)^{\mathbb{I}}$ \\
\hline Triglycerides (mg/dL) & $61(45-88)$ & $79(54-120)$ & $68(49-101)^{\mathbb{I}}$ \\
\hline Fasting glucose (mg/dL) & $82.4(76.6-89.0)$ & $87.9(81.6-95.7)$ & $84.8(78.1-92.2)$ II \\
\hline Fasting insulin $(\mu \mathrm{U} / \mathrm{L})$ & $6.4(4.3-9.7)$ & $6.5(4.1-9.6)$ & $6.4(4.2-9.6)$ \\
\hline HOMA-Index & $1.3(0.9-2.0)$ & $1.4(0.9-2.2)$ & $1.3(0.9-2.1)^{\#}$ \\
\hline $\mathrm{TSH}(\mu \mathrm{UI} / \mathrm{mL})$ & $1.7(1.2-2.4)$ & $1.5(1.0-2.0)$ & $1.6(1.1-2.2)^{\mathbb{I}}$ \\
\hline FT4 (ng/dL) & $1.3(1.2-1.4)$ & $1.3(1.2-1.4)$ & $1.3(1.2-1.4)^{\mathbb{I}}$ \\
\hline Leptin $(\mathrm{pg} / \mathrm{mL})$ & 7492 (3530-13052) & $3080(1250-5660)$ & $4910(2040-9970)$ \\
\hline Adiponectin (mg/dL) & $2.8(1.9-3.8)$ & $1.8(1.2-2.6)$ & $2.3(1.5-3.4)^{\mathbb{I I}}$ \\
\hline Leptin/adiponectin & $2640(1046-5424)$ & 1577 (583-3697) & $2116(778-4690)^{\mathbb{I I}}$ \\
\hline Metabolic syndrome $(n, \%)$ & $94,3.0 \%$ & $108,5.1 \%$ & $202,4.3 \%$ \\
\hline
\end{tabular}

Continuous data are given as median and interquartile range; categorical data are expressed as absolute and relative frequencies. Continuous variables were compared using Mann-Whitney U test. Categorical variables were compared with Pearson $\chi 2$ test. Abbreviations: BMI, body mass index; SBP, systolic blood pressure; DBP, diastolic blood pressure; LDL, low density cholesterol; HDL, high density cholesterol; HOMA, homeostatic model assessment; TSH, thyrotropin; FT4, free thyroxine. ${ }^{\#} p<0.01$; ${ }^{\mathbb{I I}} p<0.001$.

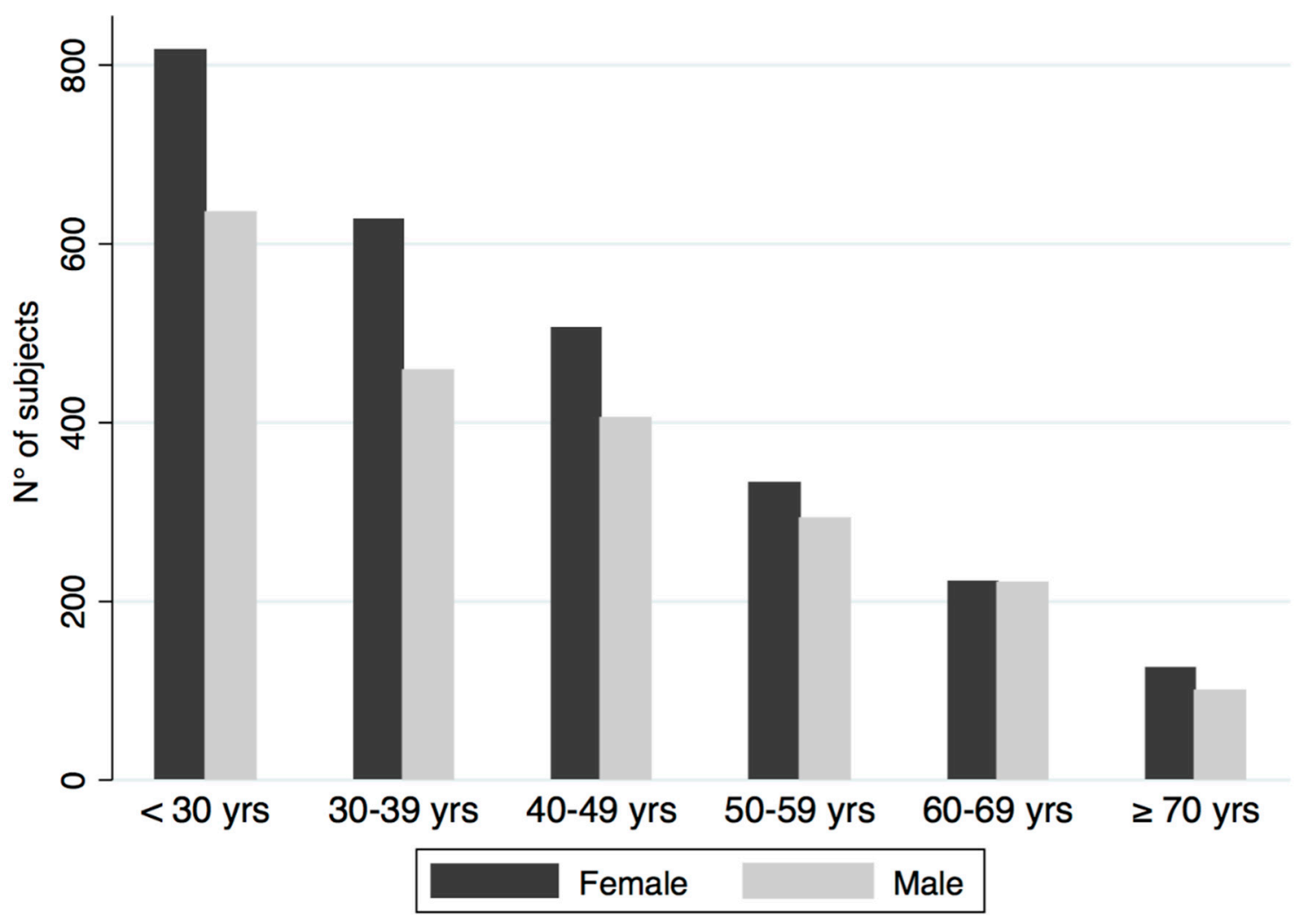

Figure 1. Age decades accordingly to gender. 
Table 2 showed the comparison between thyroid hormones and cytokines accordingly to the presence of MS, stratified by gender. Subjects with MS had increased leptin and 1/a and reduced adiponectin levels.

Table 2. Comparison between thyroid hormones and cytokines in subjects with and without metabolic syndrome, stratified by gender.

\begin{tabular}{ccccc}
\hline & \multicolumn{2}{c}{ Female } & Male \\
\cline { 2 - 5 } & MS & No MS & MS & No MS \\
\hline Leptin $(\mathrm{pg} / \mathrm{mL})$ & $1,3400(6530-2,5080)^{\text {II }}$ & $7355(3483-1,2798)$ & $5840(2310-1,0300)^{\text {II }}$ & $2980(1194-5474)$ \\
Adiponectin $(\mathrm{mg} / \mathrm{dL})$ & $2.29(1.67-3.28)^{\#}$ & $2.79(1.96-3.85)$ & $1.52(1.17-2.41)^{*}$ & $1.81(1.26-2.66)$ \\
$1 / \mathrm{a}$ & $5742(1355-1,3463)^{\text {II }}$ & $2607(1034-5276)$ & $3703(1355-6732)$ & $1497(569-3494)^{\text {II }}$ \\
TSH $(\mu \mathrm{UL} / \mathrm{mL})$ & $1.44(0.84-2.26)^{\#}$ & $1.74(1.19-2.40)$ & $1.39(1.05-2.00)$ & $1.49(1.03-2.05)$ \\
FT4 $(\mathrm{ng} / \mathrm{dL})$ & $1.26(1.16-1.40)$ & $1.28(1.18-1.40)$ & $1.25(1.13-1.37)$ & $1.30(1.19-1.43)^{\#}$ \\
\hline
\end{tabular}

Data are presented as median and interquartile range. Variables were compared, separately for male and female, accordingly to presence/absence of MS using Mann-Whitney U test. Abbreviations: MS, metabolic syndrome; $1 / \mathrm{a}$, leptin/adiponectin ratio; TSH, thyrotropin; FT4, free thyroxine. ${ }^{*} p<0.05$; ${ }^{\#} p<0.01$; ${ }^{\mathbb{I}} p<0.001$.

Table 3 showed the result of multiple linear regression models in female. In model 1, adjusted for age, sex, overweight, and HOMA index, TSH was significantly and positively associated with triglycerides $(\beta=0.081, p<0.001)$. On the contrary, waist circumference, SBP, DBP, and fasting glucose were not associated with TSH. Addition of the cytokines and their ratio to the regression models did not substantially change the impact of TSH levels on triglycerides $(\beta=0.081, p<0.001)$. As for FT4, model 1 showed that it was positively associated with $\operatorname{HDL}(\beta=0.056, p<0.01), \operatorname{SBP}(\beta=0.059, p<0.001)$, $\operatorname{DBP}(\beta=0.044, p<0.01)$, and fasting glucose $(\beta=0.046, p<0.01)$. Conversely, FT4 showed a negative association with waist circumference $(\beta=-0.052, p<0.001)$. Addition of the leptin and adiponectin to the multivariable regression model 1 , attenuated the impact of FT4 on HDL $(\beta=0.048, p<0.05)$, waist circumference $(\beta=-0.044, p<0.01)$ and total cholesterol $(\beta=0.031, p=n s)$, while enhanced its effect on DBP $(\beta=0.044, p<0.01)$, fasting glucose $(\beta=0.050, p<0.01)$. In Model 3, 1/a was negatively associated with $\operatorname{HDL}(\beta=-0.135, p<0.001)$ and showed a positive association with waist circumference $(\beta=0.150, p<0.001)$, SBP $(\beta=0.047, p<0.01)$ and $\mathrm{DBP}(\beta=0.079, p<0.001)$.

Table 3. Association of thyroid function with components of the metabolic syndrome in female.

\begin{tabular}{|c|c|c|c|c|c|c|c|c|c|}
\hline & Model & TSH & Leptin & Adiponectin & $1 / a$ & FT4 & Leptin & Adiponectin & $1 / a$ \\
\hline \multirow{3}{*}{ HDL } & 1 & 0.011 & - & - & - & $0.056^{\#}$ & - & - & - \\
\hline & 2 & 0.020 & $-0.059 \mathbb{I I}$ & $0.156^{\mathbb{I I}}$ & - & $0.048^{*}$ & $-0.056^{\#}$ & 0.153 II & - \\
\hline & 3 & 0.020 & - & - & $-0.138^{\text {II }}$ & $0.052^{\#}$ & - & - & $-0.135^{\mathbb{I I}}$ \\
\hline \multirow{3}{*}{ Triglycerides } & 1 & $0.081 \mathbb{I}$ & - & - & - & -0.021 & - & - & - \\
\hline & 2 & $0.081 \mathbb{I}$ & -0.034 & $-0.041 *$ & - & -0.021 & -0.029 & $-0.041 *$ & - \\
\hline & 3 & $0.079 \mathbb{I I}$ & - & - & 0.011 & -0.021 & - & - & 0.014 \\
\hline \multirow{3}{*}{ Waist } & 1 & 0.002 & - & - & - & $-0.052 \mathbb{I}$ & - & - & - \\
\hline & 2 & -0.011 & $0.175^{\mathbb{I I}}$ & $-0.042 \mathbb{I I}$ & - & $-0.044^{\#}$ & $0.173^{\mathbb{I}}$ & $-0.040^{\#}$ & - \\
\hline & 3 & -0.006 & - & - & $0.152^{\text {II }}$ & $-0.046^{\text {II }}$ & - & - & $0.150 \mathbb{I I}$ \\
\hline \multirow{3}{*}{ SBP } & 1 & 0.009 & - & - & - & $0.059 \mathbb{I I}$ & - & - & - \\
\hline & 2 & 0.007 & $0.062^{\text {II }}$ & 0.025 & - & $0.059 \mathbb{I I}$ & $0.065^{\#}$ & 0.022 & - \\
\hline & 3 & 0.009 & - & - & $0.044^{\#}$ & 0.060 II & - & - & $0.047^{\#}$ \\
\hline \multirow{3}{*}{ DBP } & 1 & 0.024 & - & - & - & $0.044^{\#}$ & - & - & - \\
\hline & 2 & 0.023 & $0.083 \mathbb{I I}$ & 0.013 & - & $0.046^{\#}$ & $0.086^{\mathbb{I}}$ & -0.011 & - \\
\hline & 3 & 0.024 & - & - & $0.076^{\mathbb{I I}}$ & $0.047^{\#}$ & - & - & $0.079 \mathbb{I I}$ \\
\hline \multirow{3}{*}{ Fasting glucose } & 1 & -0.015 & - & - & - & $0.046^{\#}$ & - & - & - \\
\hline & 2 & -0.016 & -0.012 & $-0.055^{\#}$ & - & 0.050 \# & -0.011 & $-0.058^{\#}$ & - \\
\hline & 3 & -0.016 & - & - & 0.022 & $0.049^{\#}$ & - & - & 0.024 \\
\hline
\end{tabular}

Values are presented as $\beta$, standardized regression coefficients. Model 1, adjusted for age, overweight, and HOMA-index. Model 2, adjusted for age, overweight, HOMA, leptin, adiponectin. Model 3, adjusted for age, overweight, HOMA, leptin-adiponectin ratio. Abbreviations: TSH, thyrotropin; FT4, free thyroxine; HDL, high density cholesterol; SBP, systolic blood pressure; DBP, diastolic blood pressure; 1/a, leptin-adiponectin ratio. ${ }^{*} p<0.05 ;{ }^{\#} p<0.01 ;{ }^{\mathbb{I I}} p<0.001$. 
Results of multiple linear regression models in male are showed in Table 4. In model 1, TSH was positively associated with triglycerides $(\beta=0.111, p<0.001)$. After addition of cytokines to the model, we observed a reduced impact of TSH on the dependent variables (triglycerides: $\beta=0.106$, $p=<0.001)$. FT4 showed a positive association with DBP $(\beta=0.51, p<0.01)$, which was not modified after the addition of leptin and adiponectin to the model. In model 3, FT4 showed the same trend of previous models and $1 / \mathrm{a}$ had a positive association with waist circumference $(\beta=0.142, p<0.001)$ and triglycerides $(\beta=0.047, p<0.05)$ and a negative correlation with HDL $(\beta=-0.141, p<0.001)$

Table 4. Association of thyroid function with components of the metabolic syndrome in male.

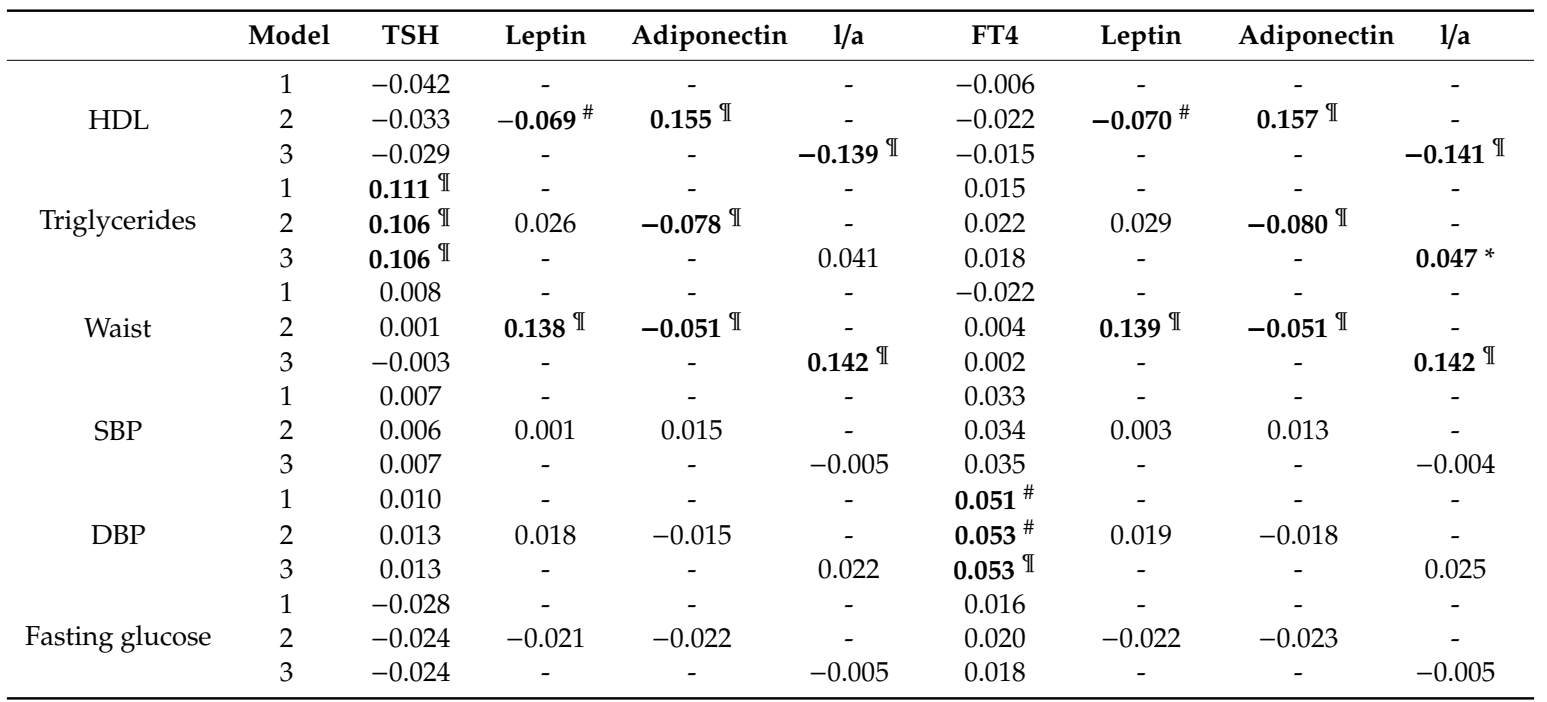

Values are presented as $\beta$, standardized regression coefficients. Model 1, adjusted for age, overweight, and HOMA-index. Model 2, adjusted for age, overweight, HOMA, leptin, adiponectin. Model 3, adjusted for age, overweight, HOMA, leptin-adiponectin ratio. Abbreviations: TSH, thyrotropin; FT4, free thyroxine; HDL, high density cholesterol; SBP, systolic blood pressure; DBP, diastolic blood pressure; 1/a, leptin-adiponectin ratio. $* p<0.05 ;{ }^{*} p<0.01 ;$ II $p<0.001$.

We further tested whether thyroid hormone increased the risk of MS. As reported in Table 5, TSH nor FT4 predicted the risk of MS.

Table 5. Effect of thyroid hormones and cytokine of metabolic syndrome: results of logistic regression.

\begin{tabular}{|c|c|c|c|c|c|c|c|c|c|}
\hline & Model & TSH & Leptin & Adiponectin & $1 / a$ & FT4 & Leptin & Adiponectin & $1 / a$ \\
\hline \multirow{2}{*}{ Female } & 1 & $\begin{array}{c}0.94 \\
(0.71-1.24)\end{array}$ & - & - & - & $\begin{array}{c}1.27 \\
(0.37-4.38)\end{array}$ & - & - & - \\
\hline & 2 & $\begin{array}{c}0.89 \\
(0.67-1.18)\end{array}$ & $\begin{array}{c}1.00 \\
(1.00-1.00)\end{array}$ & $\begin{array}{c}0.78 \\
(0.67-0.91) \text { II }\end{array}$ & 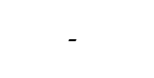 & $\begin{array}{c}1.42 \\
(0.40-5.05)\end{array}$ & $\begin{array}{c}1.00 \\
(1.00-1.00)\end{array}$ & $\begin{array}{c}0.78 \\
(0.67-0.91) \text { II }\end{array}$ & - \\
\hline \multirow{4}{*}{ Male } & 3 & $\begin{array}{c}0.89 \\
(0.67-1.18)\end{array}$ & 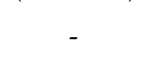 & 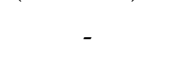 & $\begin{array}{c}1.00 \\
(1.00-1.00)\end{array}$ & $\begin{array}{c}1.51 \\
(0.43-5.31)\end{array}$ & - & - & $\begin{array}{c}1.00 \\
(1.00-1.00)\end{array}$ \\
\hline & 1 & $\begin{array}{c}1.26 \\
(0.93-1.69)\end{array}$ & - & - & The & $\begin{array}{c}1.83 \\
(0.54-6.17)\end{array}$ & - & - & $x^{\prime}$ \\
\hline & 2 & $\begin{array}{c}1.19 \\
(0.87-1.63)\end{array}$ & $\begin{array}{c}1.00 \\
(1.00-1.00)\end{array}$ & $\begin{array}{c}0.82 \\
(0.67-1.00)\end{array}$ & - & $\begin{array}{c}2.19 \\
(0.63-7.60)\end{array}$ & $\begin{array}{c}1.00 \\
(1.00-1.00)\end{array}$ & $\begin{array}{c}0.80 \\
(0.65-0.98)\end{array}$ & - \\
\hline & 3 & $\begin{array}{c}1.20 \\
(0.88-1.64)\end{array}$ & - & 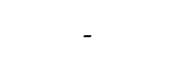 & $\begin{array}{c}1.00 \\
(1.00-1.00)\end{array}$ & $\begin{array}{c}1.79 \\
(0.52-6.11)\end{array}$ & - & - & $\begin{array}{c}1.00 \\
(1.00-1.00)\end{array}$ \\
\hline
\end{tabular}

Values are presented as Odds Ratio and 95\% confidence interval. Model 1, adjusted for age, overweight, and HOMA-index. Model 2, adjusted for age, overweight, HOMA, leptin, adiponectin. Model 3, adjusted for age, overweight, HOMA, leptin-adiponectin ratio. Abbreviations: TSH, thyrotropin; FT4, free thyroxine; HDL, high density cholesterol; SBP, systolic blood pressure; DBP, diastolic blood pressure; 1/a, leptin-adiponectin ratio. ${ }^{*} p<0.05 ;$ व $p<0.001$.

Finally, we tested interaction terms in all statistical models. Interaction between thyroid hormones (FT4 or TSH) with cytokines (leptin, or adiponectin, or 1/a) was not significant in male as well in female. 


\section{Discussion}

In this study we aimed to clarify the relation between TSH and FT4 levels with the component of the MS in euthyroid male and female without thyroid diseases. The present population-based survey indicates a clear gender effect on the association between components of MS and thyroid hormones. Indeed, in female five out six components were associated with FT4 and 1 out 6 with TSH. On the contrary, in male, only DBP was associated with FT4, while TSH was associated with LDL and triglycerides.

Hormones play a pivotal role in adipocytes metabolism [28,29], and thyroid hormones upregulate many metabolic pathways relevant for resting energy expenditure. In particular, hyperthyroidism is associated with weight loss despite increased appetite and elevated metabolic rate, whereas hypothyroidism is related to a modest weight gain and decreased metabolic rate. Less clear are the potential mechanisms underlying the association between thyroid function and body fat in euthyroid individuals, although TSH and BMI might be positively correlated. Several cross-sectional studies have reported associations of body fat with higher serum TSH and T3 and lower T4 among euthyroid individuals [30,31], although with some inconsistencies probably related to different methodologic approaches and/or small samples of participants [32]. Several causes of increased TSH levels in obesity have been suggested. Apart from the coexistence of autoimmune thyroiditis, which are highly prevalent in the general population [33], a neuroendocrine dysfunction mediated by the adipocyte derived leptin has been postulated as a cause of elevated TSH levels in obesity [34-36]. A decreased negative feed-back due to partially bio-inactive TSH or the presence of a partial hormone resistance due a decrease in $\mathrm{T} 3$ receptors have both been suggested, although experimental studies providing this hypothesis are missing and therefore these concepts are very speculative.

Many studies have assessed the association between thyroid dysfunction and the MS. Some studies concentrated only on serum TSH levels $[13,37]$ or evaluated MS components individually and not the syndrome as whole [14]. However, variable correlations between serum TSH, thyroid hormones and components of the MS have been found in these cross-sectional studies [17,38]. Other studies suggested an increased risk of MS in patients with elevated TSH levels $[39,40]$, whereas FT4 levels have been shown to be associated with four of the five components of the MS [15]. More recently, no significant associations between serum TSH levels and prevalence of MS or individual components of the MS in obese and overweight individual have been reported [41]. However, no serum FT4 levels were available in this study and no associations between FT4 and individual component of the MT could be done.

We found a positive association between FT4 and blood pressure in both female and male, although the latter only with DBP. An association between FT4 and blood pressure has been reported in several studies and could be due to the effect of thyroid hormone on cardiovascular system. Indeed, excess of thyroid hormone increases caused a decrease of systemic vascular resistance and an increase of heart rate and contractility, thus increasing SBP [9]. In addition, a possible endothelial dysfunction has been postulated by some authors [42]. However, the duration of this effect is still not clear, as suggested by Itterman who found an association between subclinical hyperthyroidism and current, but not incident, hypertension in a pooled data analysis [43]. A synergistic effect of increased arterial stiffness has been also postulated [44-46].

In our study we found a positive association between TSH and triglycerides, both in male and female. The action of thyroid hormone on lipid metabolism has been well documented and is due to different mechanisms. Thyroid hormone stimulates the transcription of the low-density lipoprotein cholesterol (LDL) receptor gene, induces the hepatic expression of hydroxymethylglutaryl coenzyme A reductase (HMG-CoA), increases the expression of the sterol regulatory element-binding protein-2 (SREBP-2) that in turn modulates expression of LDL receptor. Thyroid hormone may contribute to maintain cholesterol homeostasis through the conversion of cholesterol to bile acids and subsequent faecal, and also decreases cholesterol ester transfer protein (CEPT) concentrations, acting in HDL 
metabolism. Finally, lipoprotein lipase activity is increased by thyroid hormone [10]. The gender effect on this association has been recently studied $[47,48]$ and our findings are in line with previous reports.

We also showed that FT4 has a direct and positive association with fasting glucose in female. While the role of thyroid hormone on glucose metabolism has been well documented, the reason of this gender effect will require more studies, although it is logical to believe a central role of sex hormones [49], as clinically evident in women with polycystic ovary syndrome who has at increased risk to develop insulin resistance and diabetes [9].

Finally, we also found that serum FT4 concentration in euthyroid female was negatively associated with waist circumference in female, suggesting that lower FT4 might be related to visceral obesity, thus predisposing to insulin resistance. Thyroid hormone modulates the activity of different metabolic pathways associated with the basal metabolic rate, such as uncoupling of cellular metabolism from adenosine triphosphate (ATP) synthesis or modifying metabolic process downstream from mitochondria [50].

Previous studies hypothesized that the effect of thyroid hormone on MS could be associated with abnormal adipocytokine production. Our study clearly showed that the effect of the most abundant cytokines (leptin and adiponectin) have an addictive and independent effect on this association, rather than a causal effect. We can only speculate that other mechanisms (e.g., different cytokines) may explain the role of thyroid hormones on MS. Similarly to previous studies, we also demonstrated the importance of 1/a on components of metabolic syndrome [51]. Indeed, we found that 1/a are associated with almost all the components of MS although with gender difference.

The overall frequency of MS in our sample was lower than what already reported, but this is due to the tight exclusion criteria we used. Indeed, we did not include subjects taking glucose lowering and hypotensive medication as well as those on lipid-lowering drugs, thus excluding a high number of subjects that fulfil the ATP III criteria of MS. The different results observed in other studies may be caused by variations in the definition of MS, differences in sample size as well as thyroid status, since some studies reported a higher prevalence of subclinical hypothyroidism, whereas our population was clearly euthyroid and without subclinical thyroid diseases.

There are some limitations in this study. Due to the cross-sectional design, we were limited in our ability to assess the timing of the association between the accumulation of body fat and variations in FT4 levels. Moreover, although waist circumference cannot accurately distinguish visceral fat from subcutaneous adipose tissue, thyroid hormones should be evaluated in relation to visceral adiposity to understand the relationships between thyroid hormones and insulin resistance. Further, all the subjects had only one assessment of TSH and FT4 (but not free triiodothyronine), thus potentially including individuals with non-thyroidal illness or transient abnormality. However, the strengths of our study include the relatively large sample size from a homogeneous population, and tight exclusion criteria.

In summary, we observe a clear gender effect on the association between thyroid hormones and the components of MS. Although changes in body fat are well known consequences of overt thyroid dysfunction, our data suggest that, even within the euthyroid range, excess of truncal adipose tissue is associated with variations in both TSH and FT4 levels. Leptin and adiponectin exert an additive effect in this association and not a causal effect. Experimental and/or further prospective studies should be performed in order to determine the clinical significance of our findings in euthyroid states.

Author Contributions: Formal analysis, A.P.D.; writing—original draft preparation, A.P.D.; writing-review and editing, A.S., E.F., D.S.; supervision, E.G.L., F.C.; project administration, F.C.; funding acquisition, D.S., F.C., E.G.L.

Acknowledgments: This work was supported by the National Institute on Aging [Contract NO1-AG-1-2109] and in part by the Intramural Research Program of the NIH, National Institute on Aging.

Conflicts of Interest: The authors declare no conflict of interest. 


\section{References}

1. Scuteri, A.; Orru, M.; Morrell, C.; Piras, M.G.; Taub, D.; Schlessinger, D.; Uda, M.; Lakatta, E.G. Independent and additive effects of cytokine patterns and the metabolic syndrome on arterial aging in the SardiNIA Study. Atherosclerosis 2011, 215, 459-464. [CrossRef]

2. Farasat, S.M.; Morrell, C.H.; Scuteri, A.; Ting, C.T.; Yin, F.C.; Spurgeon, H.A.; Chen, C.H.; Lakatta, E.G.; Najjar, S.S. Pulse pressure is inversely related to aortic root diameter implications for the pathogenesis of systolic hypertension. Hypertension 2008, 51, 196-202. [CrossRef] [PubMed]

3. Scuteri, A.; Morrell, C.H.; Orru, M.; AlGhatrif, M.; Saba, P.S.; Terracciano, A.; Ferreli, L.A.; Loi, F.; Marongiu, M.; Pilia, M.G.; et al. Gender specific profiles of white coat and masked hypertension impacts on arterial structure and function in the SardiNIA study. Int. J. Cardiol. 2016, 217, 92-98. [CrossRef] [PubMed]

4. Alberti, K.G.; Eckel, R.H.; Grundy, S.M.; Zimmet, P.Z.; Cleeman, J.I.; Donato, K.A.; Fruchart, J.C.; James, W.P.; Loria, C.M.; Smith, S.C., Jr.; et al. Harmonizing the metabolic syndrome: A joint interim statement of the International Diabetes Federation Task Force on Epidemiology and Prevention; National Heart, Lung, and Blood Institute; American Heart Association; World Heart Federation; International Atherosclerosis Society; and International Association for the Study of Obesity. Circulation 2009, 120, 1640-1645.

5. Scuteri, A.; Franco, O.H.; Majiid, A.; Jolita, B.; Sergey, B.; Cheng, H.M.; Chen, C.H.; Choi, S.W.; Francesco, C.; De Buyzere, M.L.; et al. The relationship between the metabolic syndrome and arterial wall thickness: A mosaic still to be interpreted. Atherosclerosis 2016, 255, 11-16. [CrossRef]

6. Klein, I.; Ojamaa, K. Thyroid hormone and the cardiovascular system. N. Engl. J. Med. 2001, 344, 501-509. [CrossRef]

7. Biondi, B.; Palmieri, E.A.; Lombardi, G.; Fazio, S. Effects of subclinical thyroid dysfunction on the heart. Ann. Intern. Med. 2002, 137, 904-914. [CrossRef]

8. Delitala, A.P.; Filigheddu, F.; Orru, M.; AlGhatrif, M.; Steri, M.; Pilia, M.G.; Scuteri, A.; Lobina, M.; Piras, M.G.; Delitala, G.; et al. No evidence of association between subclinical thyroid disorders and common carotid intima medial thickness or atherosclerotic plaque. Nutr. Metab. Cardiovasc. Dis. 2015, 25, 1104-1110. [CrossRef] [PubMed]

9. Delitala, A.P. Subclinical Hyperthyroidism and the Cardiovascular Disease. Horm. Metab. Res. 2017, 49, 723-731. [CrossRef]

10. Delitala, A.P.; Fanciulli, G.; Maioli, M.; Delitala, G. Subclinical hypothyroidism, lipid metabolism and cardiovascular disease. Eur. J. Intern. Med. 2017, 38, 17-24. [CrossRef] [PubMed]

11. Jackson, I.M.; Prentice, C.R.; McKiddie, M.T. The effect of hypothyroidism on glucose tolerance and insulin metabolism. J. Endocrinol. 1970, 47, 257-258. [CrossRef]

12. Delitala, A.P.; Fanciulli, G.; Pes, G.M.; Maioli, M.; Delitala, G. Thyroid Hormones, Metabolic Syndrome and Its Components. Endocr. Metab. Immune Disord. Drug Targets 2017, 17, 56-62. [CrossRef]

13. Oh, J.Y.; Sung, Y.A.; Lee, H.J. Elevated thyroid stimulating hormone levels are associated with metabolic syndrome in euthyroid young women. Korean J. Intern. Med. 2013, 28, 180-186. [CrossRef]

14. Lee, Y.K.; Kim, J.E.; Oh, H.J.; Park, K.S.; Kim, S.K.; Park, S.W.; Kim, M.J.; Cho, Y.W. Serum TSH level in healthy Koreans and the association of TSH with serum lipid concentration and metabolic syndrome. Korean J. Intern. Med. 2011, 26, 432-439. [CrossRef]

15. Roos, A.; Bakker, S.J.; Links, T.P.; Gans, R.O.; Wolffenbuttel, B.H. Thyroid function is associated with components of the metabolic syndrome in euthyroid subjects. J. Clin. Endocrinol. Metab. 2007, 92, 491-496. [CrossRef]

16. Lin, S.Y.; Wang, Y.Y.; Liu, P.H.; Lai, W.A.; Sheu, W.H. Lower serum free thyroxine levels are associated with metabolic syndrome in a Chinese population. Metabolism 2005, 54, 1524-1528. [CrossRef]

17. Garduno-Garcia Jde, J.; Alvirde-Garcia, U.; Lopez-Carrasco, G.; Padilla Mendoza, M.E.; Mehta, R.; Arellano-Campos, O.; Choza, R.; Sauque, L.; Garay-Sevilla, M.E.; Malacara, J.M.; et al. TSH and free thyroxine concentrations are associated with differing metabolic markers in euthyroid subjects. Eur. J. Endocrinol. 2010, 163, 273-278. [CrossRef]

18. Kim, B.J.; Kim, T.Y.; Koh, J.M.; Kim, H.K.; Park, J.Y.; Lee, K.U.; Shong, Y.K.; Kim, W.B. Relationship between serum free T4 (FT4) levels and metabolic syndrome (MS) and its components in healthy euthyroid subjects. Clin. Endocrinol. 2009, 70, 152-160. [CrossRef] 
19. Uslu, S.; Kebapci, N.; Kara, M.; Bal, C. Relationship between adipocytokines and cardiovascular risk factors in patients with type 2 diabetes mellitus. Exp. Ther. Med. 2012, 4, 113-120. [CrossRef]

20. Iwashima, Y.; Katsuya, T.; Ishikawa, K.; Ouchi, N.; Ohishi, M.; Sugimoto, K.; Fu, Y.; Motone, M.; Yamamoto, K.; Matsuo, A.; et al. Hypoadiponectinemia is an independent risk factor for hypertension. Hypertension 2004, 43, 1318-1323. [CrossRef]

21. Spranger, J.; Kroke, A.; Mohlig, M.; Bergmann, M.M.; Ristow, M.; Boeing, H.; Pfeiffer, A.F. Adiponectin and protection against type 2 diabetes mellitus. Lancet 2003, 361, 226-228. [CrossRef]

22. Oda, N.; Imamura, S.; Fujita, T.; Uchida, Y.; Inagaki, K.; Kakizawa, H.; Hayakawa, N.; Suzuki, A.; Takeda, J.; Horikawa, Y.; et al. The ratio of leptin to adiponectin can be used as an index of insulin resistance. Metabolism 2008, 57, 268-273. [CrossRef]

23. Delitala, A.P.; Terracciano, A.; Fiorillo, E.; Orru, V.; Schlessinger, D.; Cucca, F. Depressive symptoms, thyroid hormone and autoimmunity in a population-based cohort from Sardinia. J. Affect. Disord. 2016, 191, 82-87. [CrossRef]

24. Talameh, Y.; Wei, R.; Naito, H. Measurement of total HDL, HDL 2 and $\mathrm{HDL}_{3}$ by dextran sulfate- $\mathrm{MgCl}_{2}$ precipitation technique in human serum. Clin. Chim. Acta 1986, 158, 33-41. [CrossRef]

25. Friedewald, W.T.; Levy, R.I.; Fredrickson, D.S. Estimation of the concentration of low-density lipoprotein cholesterol in plasma, without use of the preparative ultracentrifuge. Clin. Chem. 1972, 18, 499-502.

26. Matthews, D.R.; Hosker, J.P.; Rudenski, A.S.; Naylor, B.A.; Treacher, D.F.; Turner, R.C. Homeostasis model assessment: Insulin resistance and beta-cell function from fasting plasma glucose and insulin concentrations in man. Diabetologia 1985, 28, 412-419. [CrossRef]

27. Expert Panel on Detection, Evaluation, and Treatment of High Blood Cholesterol in Adults. Expert Panel on Detection, E., Treatment of High Blood Cholesterol in, A. Executive Summary of The Third Report of The National Cholesterol Education Program (NCEP) Expert Panel on Detection, Evaluation, And Treatment of High Blood Cholesterol in Adults (Adult Treatment Panel III). JAMA 2001, 285, 2486-2497.

28. Basoli, V.; Santaniello, S.; Cruciani, S.; Ginesu, G.C.; Cossu, M.L.; Delitala, A.P.; Serra, P.A.; Ventura, C.; Maioli, M. Melatonin and Vitamin D Interfere with the Adipogenic Fate of Adipose-Derived Stem Cells. Int. J. Mol. Sci. 2017, 18, 981. [CrossRef]

29. Panda, S. Circadian physiology of metabolism. Science 2016, 354, 1008-1015. [CrossRef]

30. Asvold, B.O.; Bjoro, T.; Vatten, L.J. Association of serum TSH with high body mass differs between smokers and never-smokers. J. Clin. Endocrinol. Metab. 2009, 94, 5023-5027. [CrossRef]

31. De Pergola, G.; Ciampolillo, A.; Paolotti, S.; Trerotoli, P.; Giorgino, R. Free triiodothyronine and thyroid stimulating hormone are directly associated with waist circumference, independently of insulin resistance, metabolic parameters and blood pressure in overweight and obese women. Clin. Endocrinol. 2007, 67, 265-269. [CrossRef] [PubMed]

32. Kitahara, C.M.; Platz, E.A.; Ladenson, P.W.; Mondul, A.M.; Menke, A.; Berrington de Gonzalez, A. Body fatness and markers of thyroid function among U.S. men and women. PLoS ONE 2012, 7, e34979. [CrossRef] [PubMed]

33. Delitala, A.P.; Pilia, M.G.; Ferreli, L.; Loi, F.; Curreli, N.; Balaci, L.; Schlessinger, D.; Cucca, F. Prevalence of unknown thyroid disorders in a Sardinian cohort. Eur. J. Endocrinol. 2014, 171, 143-149. [CrossRef] [PubMed]

34. Winter, W.E.; Signorino, M.R. Review: Molecular thyroidology. Ann. Clin. Lab. Sci. 2001, 31, 221-244.

35. Mantzoros, C.S. The role of leptin and hypothalamic neuropeptides in energy homeostasis: Update on leptin in obesity. Growth Horm. IGF Res. 2001, 11 (Suppl. 1), S85-S89. [CrossRef]

36. Delitala, A.P.; Steri, M.; Fiorillo, E.; Marongiu, M.; Lakatta, E.G.; Schlessinger, D.; Cucca, F. Adipocytokine correlations with thyroid function and autoimmunity in euthyroid sardinians. Cytokine 2018, 111, 189-193. [CrossRef] [PubMed]

37. Ruhla, S.; Weickert, M.O.; Arafat, A.M.; Osterhoff, M.; Isken, F.; Spranger, J.; Schofl, C.; Pfeiffer, A.F.; Mohlig, M. A high normal TSH is associated with the metabolic syndrome. Clin. Endocrinol. 2010, 72, 696-701. [CrossRef]

38. Luna-Vazquez, F.; Cruz-Lumbreras, R.; Rodriguez-Castelan, J.; Cervantes-Rodriguez, M.; Rodriguez-Antolin, J.; Arroyo-Helguera, O.; Castelan, F.; Martinez-Gomez, M.; Cuevas, E. Association between the serum concentration of triiodothyronine with components of metabolic syndrome, cardiovascular risk, and diet in euthyroid post-menopausal women without and with metabolic syndrome. Springerplus 2014, 3, 266. [CrossRef] 
39. Waring, A.C.; Rodondi, N.; Harrison, S.; Kanaya, A.M.; Simonsick, E.M.; Miljkovic, I.; Satterfield, S.; Newman, A.B.; Bauer, D.C. Health, Ageing, and Body Composition Study. Thyroid function and prevalent and incident metabolic syndrome in older adults: The Health, Ageing and Body Composition Study. Clin. Endocrinol. 2012, 76, 911-918. [CrossRef]

40. Park, H.T.; Cho, G.J.; Ahn, K.H.; Shin, J.H.; Hong, S.C.; Kim, T.; Hur, J.Y.; Kim, Y.T.; Lee, K.W.; Kim, S.H. Thyroid stimulating hormone is associated with metabolic syndrome in euthyroid postmenopausal women. Maturitas 2009, 62, 301-305. [CrossRef]

41. Kommareddy, S.; Lee, S.Y.; Braverman, L.E.; Pearce, E.N. Thyroid Function and Metabolic Syndrome: A Cross-Sectional Study in Obese and Overweight Patients. Endocr. Pract. 2015, 21, 1204-1210. [CrossRef]

42. Poplawska-Kita, A.; Siewko, K.; Telejko, B.; Modzelewska, A.; Mysliwiec, J.; Milewski, R.; Gorska, M.; Szelachowska, M. The changes in the endothelial function and haemostatic and inflammatory parameters in subclinical and overt hyperthyroidism. Int. J. Endocrinol. 2013, 2013, 981638. [CrossRef]

43. Ittermann, T.; Tiller, D.; Meisinger, C.; Agger, C.; Nauck, M.; Rettig, R.; Hofman, A.; Jorgensen, T.; Linneberg, A.; Witteman, J.C.; et al. High serum thyrotropin levels are associated with current but not with incident hypertension. Thyroid 2013, 23, 955-963. [CrossRef]

44. Svare, A.; Nilsen, T.I.; Bjoro, T.; Asvold, B.O.; Langhammer, A. Serum TSH related to measures of body mass: Longitudinal data from the HUNT Study, Norway. Clin. Endocrinol. 2011, 74, 769-775. [CrossRef]

45. Ittermann, T.; Thamm, M.; Wallaschofski, H.; Rettig, R.; Volzke, H. Serum thyroid-stimulating hormone levels are associated with blood pressure in children and adolescents. J. Clin. Endocrinol. Metab. 2012, 97, 828-834. [CrossRef]

46. Delitala, A.P.; Orru, M.; Filigheddu, F.; Pilia, M.G.; Delitala, G.; Ganau, A.; Saba, P.S.; Decandia, F.; Scuteri, A.; Marongiu, M.; et al. Serum free thyroxine levels are positively associated with arterial stiffness in the SardiNIA study. Clin. Endocrinol. 2015, 82, 592-597. [CrossRef]

47. Delitala, A.P.; Steri, M.; Pilia, M.G.; Dei, M.; Lai, S.; Delitala, G.; Schlessinger, D.; Cucca, F. Menopause modulates the association between thyrotropin levels and lipid parameters: The SardiNIA study. Maturitas 2016, 92, 30-34. [CrossRef]

48. Meisinger, C.; Ittermann, T.; Tiller, D.; Agger, C.; Nauck, M.; Schipf, S.; Wallaschofski, H.; Jorgensen, T.; Linneberg, A.; Thiery, J.; et al. Sex-specific associations between thyrotropin and serum lipid profiles. Thyroid 2014, 24, 424-432. [CrossRef]

49. Gambineri, A.; Pelusi, C. Sex hormones, obesity and type 2 diabetes: Is there a link? Endocr. Connect. 2019, 8, R1-R9. [CrossRef]

50. Fontenelle, L.C.; Feitosa, M.M.; Severo, J.S.; Freitas, T.E.; Morais, J.B.; Torres-Leal, F.L.; Henriques, G.S.; do Nascimento Marreiro, D. Thyroid Function in Human Obesity: Underlying Mechanisms. Horm. Metab. Res. 2016, 48, 787-794. [CrossRef]

51. Asakawa, H.; Tokunaga, K.; Kawakami, F. Relationship of leptin level with metabolic disorders and hypertension in Japanese type 2 diabetes mellitus patients. J. Diabetes Complicat. 2001, 15, 57-62. [CrossRef] 